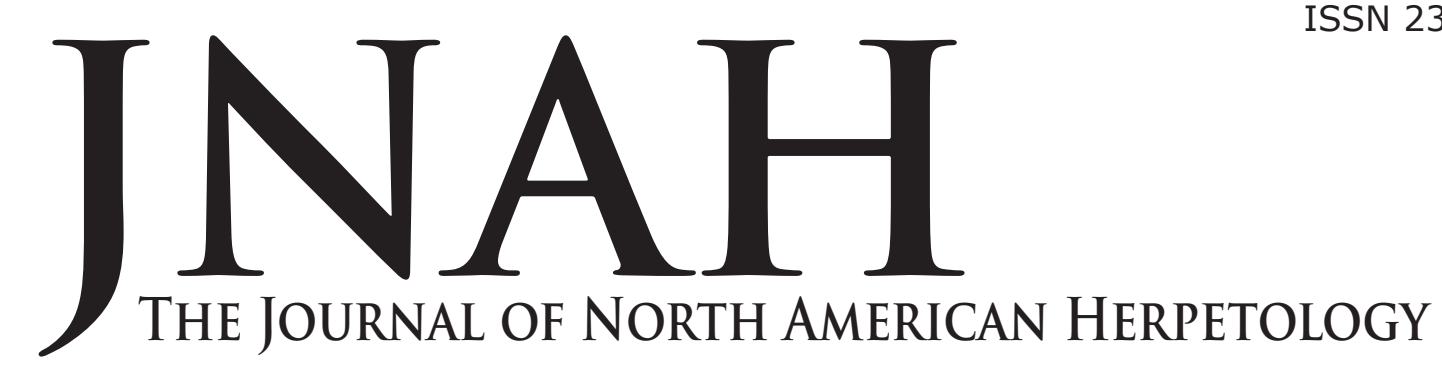

\author{
Volume 2014(1): 76-80 \\ 31 January 2014 \\ jnah.cnah.org
}

\title{
CHARACTERISTICS OF MANGROVE DIAMONDBACK TERRAPINS (MALACLEMYS TERRAPIN RHIZOPHORARUM) INHABITING ALTERED AND NATURAL MANGROVE ISLANDS
}

\author{
BRIAN K. MEALEY ${ }^{1}$, JOHN D. BALDWIN ${ }^{2}$, GRETA B.PARKS-MEALEY ${ }^{3}$, GREGORY D. BOSSART ${ }^{4}$, \\ AND MICHAEL R. J. FORSTNER ${ }^{5}$ \\ ${ }^{1}$ Institute of Wildlife Sciences, Falcon Batchelor Division of Research, 16531 SW 81 Avenue, Village \\ of Palmetto Bay, Florida 33157 and Florida Atlantic University, Division of Biological Science, 2912 \\ College Avenue, Davie, FL 33314. bmealey@palmertrinity.org \\ ${ }^{2}$ Florida Atlantic University, Division of Biological Science, 2912 College Avenue, Davie, FL 33314 \\ ${ }^{3}$ Falcon Batchelor Bird of Prey Center, Miami Museum of Science 3280 South Miami Avenue, Miami, FL \\ 33129 \\ ${ }^{4}$ Georgia Aquarium, 225 Baker Street NW, Atlanta, Georgia 30313 \\ ${ }^{5}$ Department of Biology, Texas State University, 240 Science Bldg, 601 University Drive, San Marcos, \\ $T X 78666$
}

\begin{abstract}
The Mangrove Diamondback Terrapin, (Malaclemys terrapin rhizophorarum) is dependent on a very broad array of the services provided by the mangrove ecosystem. We sought to evaluate both the turtles and their habitat by an integrated assessment of physical, chemical, and physiological parameters. Extreme site fidelity of the turtles to mangrove habitat was evident along with a strong female biased sex ratio. We provide blood serum values and microbial cultures as baselines from these turtles in the wild. Salmonella sp., a potentially zoonotic pathogen, was isolated from one female. Ultimately, the health of these turtle populations may be reflective of the integrity of the mangrove system on which they depend.
\end{abstract}

The Mangrove Diamondback Terrapin (Malaclemys terrapin rhizophorarum) is one of seven subspecies of Malaclemys terrapin that range along the US east coast from New Jersey (M. t. terrapin) to Texas (M. $t$. littoralis). Although the boundaries between these taxa and the number of stocks within each taxon are unclear, their population levels appear to be in decline or have not been adequately surveyed to allow their status to be determined (Seigel and Gibbons 1995). Coastal development has destroyed and degraded terrapin habitats and exploitation has severely depleted their abundance (Roosenburg 2000). South Florida mangroves host three of the seven recognized subspecies of Malaclemys terrapin in North America: the East Coast Diamondback Terrapin, (M. t. tequesta), (Biscayne Bay northward to Merritt Island), the Mangrove Diamondback Terrapin, (M. t. rhizophorarum), (lower Florida Keys west to the Marquesas) and the Ornate Diamondback Terrapin, ( $M$. t. macrospilota), (Florida Bay and on the Florida's gulf coast to Tampa Bay (Hauswaldt and Glenn 2005, Forstner et al., 2000).
Ecological and life history data are sparse for all of the Malaclemys terrapin populations in south Florida (Baldwin et al. 2005). Their presence is seldom reported on the highly altered human occupied Florida Keys. These terrapins are under tremendous pressure as a consequence of urban development resulting in decreased mangrove coastline, habitat fragmented by roadways, canals and frequent human encounters (Mealey et al., 2005). The remaining south Florida insular Malaclemys populations are found in "pockets" isolated on keys within Florida Bay, Everglades National Park and the Florida Keys National Wildlife Refuges. Primary threats to the terrapins come from habitat degradation and destruction, leading to decreases in water quality and fresh water availability. The terrapins also suffer from the established insular populations of the Black Rat, Rattus rattus, a nest raider (Draud et al., 2004).

Here we provide limited demographic data on M. t. rhizophorarum, suggesting dependency of the species on the mangrove community. We also provide integrated health assessment parameters for two disjunct wild pop- 
Table 1: Morphometric measurements $(\mathrm{mm})$ millimeters and weight $(\mathrm{g})$ grams for the terrapin, Malaclemys terrapin rhizophorarum for the study sites TLK and CKW. Measurements are for adult females and males only.

\begin{tabular}{|c|c|c|c|c|c|c|}
\hline \multirow{2}{*}{$\begin{array}{l}\text { TLK } \\
\text { Dimension }\end{array}$} & \multicolumn{3}{|c|}{ Females $(\mathrm{N}=289)$} & \multicolumn{3}{|c|}{ Males $(\mathrm{N}=55)$} \\
\hline & Mean & SD & Range & Mean & SD & Range \\
\hline$C L$ & 166.57 & 10.35 & $102-189$ & 119.81 & 5.56 & $110-135$ \\
\hline $\mathrm{CW}$ & 123.42 & 8.09 & $89-170$ & 87.92 & 4.77 & $80-103$ \\
\hline PL & 149.21 & 8.53 & $110-173$ & 101.38 & 4.77 & $93-115$ \\
\hline PW & 106.46 & 7.69 & $65-121$ & 74.49 & 7.59 & $42-90$ \\
\hline & 66.2 & 4.53 & $53-91$ & 43.92 & 3.17 & $38-53$ \\
\hline Weight & 766.45 & 122.11 & $345-1175$ & 258.36 & 48.66 & $170-420$ \\
\hline$C K W$ & \multicolumn{3}{|c|}{ Females $(N=114)$} & \multicolumn{3}{|c|}{ Males $(\mathrm{N}=8)$} \\
\hline Dimension & Mean & SD & Range & Mean & SD & Range \\
\hline $\mathrm{CL}$ & 172.28 & 8.74 & $122-196$ & 112.25 & 17.16 & $86-129$ \\
\hline $\mathrm{CW}$ & 127.37 & 6.03 & $89-140$ & 81.38 & 12.01 & $63-94$ \\
\hline PL & 154.75 & 6.94 & $115-173$ & 95.5 & 11.73 & $76-107$ \\
\hline PW & 107.5 & 5.39 & $72-120$ & 68.38 & 10.14 & $53-79$ \\
\hline BD & 68.58 & 5.01 & $41-79$ & 48.25 & 3.4 & $45-53$ \\
\hline Weight & 892.02 & 117 & $310-1150$ & 221.25 & 72.19 & $120-320$ \\
\hline
\end{tabular}

ulations of M. t. rhizophorarum in the lower Florida Keys. One population was located on a private key in a highly altered island habitat where free ranging primates and other major anthropogenic changes were present. The second population was on an undisturbed key in the Key West National Wildlife Refuge. We compare mark and recapture data, and several animal health assessment parameters to determine if there are major differences between populations of $M$. $t$. rhizophorarum from human-altered versus relatively natural mangrove habitats.

\section{METHODS}

Study sites - The two study sites were designated as TreatmentSiteLK (TLK) and ControlSiteKW (CKW). This project reports results from contemporaneous monitoring of two keys/islands in the lower Florida Keys monthly (1997-2000). The perimeters of both keys are fringed with Red Mangroves (Rhizophora mangle) and the interiors dominated by Black Mangroves (Avicennia germinans). Due to the vulnerability of $M$. $t$. rhizophorarum to collecting and harvesting, we wish to keep the study sites anonymous. TLK (40.47 ha) was privately owned when the study began with extensive damage to the Red and Black Mangrove trees due to the introduction of non-indigenous wildlife. By comparison, CKW (46.69 ha) is located in the Key West National Wildlife Refuge.

Capture techniques - TLK and CKW were visited monthly, March through December, from 1997 to 2000. M. $t$. rhizophorarum were hand caught by targeted searches of 8 person hours/month. Our surveys were restricted on TLK because of tidal fluctuations but not so on CKW. On TLK terrapin encounters often occurred at high tide while they were swimming in open shallow tidal pools but retreated into Black Mangroves as it receded. Terrapins on CKW were located by searching under shoreline debris or among the pneumatophores of the Black Mangroves.

Mark/Recapture - Each terrapin was marked with a $12 \mathrm{~mm}$ passive integrated transponder (PIT) tag (AVID, 3185 Hamner Avenue, Norco, CA 92860) following the protocols established by Camper and Dixon (1988). The PIT tags were injected in the posterior peritoneum slightly above and parallel to the plane of the plastron.

Morphometrics - Measurements were taken with Haglof calipers to the nearest millimeter. Straight-line carapace length $(C L)$, carapace width $(C W)$, plastron length $(P L)$, plastron width (PW), and body depth (BD), were record- ed as well as weight $(\mathrm{g})$ and gender for each terrapin captured. Markings, shell abnormalities, and general health and appearance were noted. Terrapins were released in the same area of capture.

Blood - After swabbing with $70 \%$ ethanol, 1-2 ml blood samples were extracted from the femoral vein using a 25 or 27 gauge needle and syringe. Field samples were stored in an ice cooler and later frozen. The blood was used for serum chemistry analyses and future genetic analysis. Fifteen serum chemistry levels were analyzed on a Johnson \& Johnson Ektachem DT II System within 30 days of sampling for: total protein (TP), albumin $(\mathrm{ALB})$, uric acid (URIC), calcium $\left(\mathrm{CA}^{2++}\right)$, glucose (GLU), phosphorus (PHOS), cholinesterase (CHE), creatine kinase (CK), lactate dehydrogenase (LDH), aspartate aminotransferase (AST), alkaline phosphatase (ALKP), sodium $\left(\mathrm{NA}^{+}\right)$, potassium $\left(\mathrm{K}^{+}\right)$, chloride $\left(\mathrm{CL}^{-}\right)$, and carbon dioxide $\left(\mathrm{CO}_{2}\right)$. Aliquots from blood samples were placed in small $1-\mathrm{ml}$ plastic blood tubes and allowed to clot for 15 minutes prior to centrifugation. Samples were centrifuged for 20 minutes and serum was transferred with a pipette to separate tubes to prevent hemolysis. Analyses followed the protocol specified in the Ektachem DT II System manual.

Bacterial Cultures - With sterile culture swabs and media in the field, we collected a sample from the cloaca of each individual turtle. The applicator was then placed in a growth medium. Caution was exercised during culture acquisition to prevent contamination. Each cloacal culture results in the isolation of one or more microbial organisms. Cultures were sent to Micrim Laboratories, Fort Lauderdale for analysis within 48 hours of sampling. Statistical Analysis - Descriptive statistics were conducted to establish means, ranges and standard deviations (SD) using JMP SAS Statistical Discovery Software, (v5.1 SAS Institute, Inc., Raleigh, North Carolina). MANOVA, ANOVA and t-tests were conducted to compare measurements and serum between the genders and populations using SPSS Statistical Software, SPSS Inc., Chicago, Illinois.

RESULTS

Capture Techniques - Nearly all terrapins (97\% of 793 encounters) were captured in the key's interior with 3\% captured swimming in less than two meters of water near shore. The interior captures occurred primarily within or 
Table 2. Serum chemistry values for 20 Mangrove Diamondback Terrapins (M. t. rhizophorarum) from the lower Florida Keys. Last column reflects existing values for other chelonian species, other than Malaclemys, as described by Mader (2006).

\begin{tabular}{|c|c|c|c|c|c|}
\hline Measure & $\mathrm{N}$ & Mean & SD & Range & Normal \\
\hline GLU (mg/dl) & 20 & 60.1 & 31.47 & $29-142$ & $60.0-100.0$ \\
\hline PHOS (mg/dl) & 18 & 4.2 & 2.9 & $1.2-12.7$ & $8.0-20.0$ \\
\hline TP (g/dl) & 13 & 3.33 & 1.09 & $2.0-4.5$ & $3.0-8.0$ \\
\hline URIC (mg/dl) & 18 & 2.03 & 0.89 & $0.4-3.1$ & $1.0-10.0$ \\
\hline ALKP (U/L) & 13 & 112.08 & 51.21 & $46-194$ & $32.0-664.0$ \\
\hline AST (U/L) & 16 & 179.44 & 72.75 & $80-321$ & $1.0-640.0$ \\
\hline $\mathrm{Ca}(\mathrm{mg} / \mathrm{dl})$ & 14 & 10.51 & 2.19 & $6.3-13.6$ & $8.0-20.0$ \\
\hline $\mathrm{CHE}(\mathrm{U} / \mathrm{ml})$ & 13 & 0.39 & 0.13 & $0.22-0.68$ & 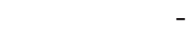 \\
\hline CK (U/L) & 11 & 402.72 & 469.84 & $39-1358$ & $27.0-2731.0$ \\
\hline LDH (U/L) & 1 & 192 & - & - & $15.0-586.0$ \\
\hline ALB $(g / d l)$ & 11 & 1.49 & 0.33 & $1.1-2.0$ & 1.6-3.1 \\
\hline $\mathrm{Na}^{+}(\mathrm{mmol} / \mathrm{L})$ & 4 & 152 & 17.8 & $131-170$ & $120.0-170.0$ \\
\hline $\mathrm{CL}^{-}(\mathrm{mmol} / \mathrm{L})$ & 9 & 103 & 8.89 & $92-115$ & $100.0-150.0$ \\
\hline $\mathrm{K}^{+}(\mathrm{mmol} / \mathrm{L})$ & 4 & 5.41 & 2.2 & $2.1-9.1$ & $2.0-8.0$ \\
\hline $\mathrm{CO}_{2}(\mathrm{mmol} / \mathrm{L})$ & 12 & 17.78 & 6.3 & $10-25$ & $12.0-18.0$ \\
\hline
\end{tabular}

at the edges of Black Mangroves (A. germinans). A total of 23 individuals marked in the 1980's in a previous study were recaptured ( $R$. Wood pers. comm. to BKM 1996). At both study sites, individual terrapins were routinely recaptured within just a few meters of previous capture points. We had several significant hurricanes during the study period, with at least one storm providing very close eyewall encounters with each of the study sites. Immediately after the storms we found few terrapins, but after several months/years the individuals increasingly reappeared in the same locations as their original captures, often to within a few to tens of meters. CKW had the slowest recovery, likely a consequence of extensive damage and die-off of $A$. germinans within the key's interior.

Mark/Recapture - Seven hundred and ninety three terrapins were encountered, captured and recaptured, during the study with 606 on TLK and 187 individuals on CKW. Combining both populations we marked and sampled 462 new individuals (336 and 126 respectively). There was a combined sex ratio of 6.39 females: 1 male at the study sites. Female biased sex ratio was much higher at CKW (14.29F:1M) than at TLK (5.25F:1M). A student t-test resulted in a significant difference in the encounters of individuals collected at the two sites ( $t=$ $3.23, \mathrm{P}=.012$ ) despite the available habitat of the two sites being very nearly the same. Total recapture rate was $70 \%$ for combined population (TLK $=80 \%$ and CKW $=48 \%$ ). One-time recaptures of an individual were $16 \%$ of the total, (TLK $=42 \%$ and $\mathrm{CKW}=32 \%$ ), two-time recaptures $7 \%($ TLK $=18 \%$ and $C K W=13 \%)$ and threetime recaptures were $3 \%($ TLK $=10 \%$ and $C K W=3 \%)$. The maximum number of recaptures of an individual was 7 times, which occurred on TLK $(<1 \%)$.

Morphometrics - A student's t-test was conducted yielding values depicting sexual dimorphism between the sexes $(P<.05)$ (Table 1$)$. TLK and CKW females were larger $(\mathrm{P}<.05)$ in two measurements: $T L K C L(T=37.5, P=$ $.001)$, TLK weight $(T=30.4, P=.001)$ and $C K W$ CL $(T=$ 17.2, $\mathrm{P}=.001)$ and $\mathrm{CKW}$ weight $(\mathrm{T}=15.5, \mathrm{P}=0.001)$. The MANOVA was significant $(F=13.51, P<.05)$ conducted on the five measurements $\mathrm{CL}, \mathrm{CW}, \mathrm{PL}, \mathrm{PW}$ and weights of the groups. All univariate ANOVA's, except for PW $(F=0.11, P=.735)$, were significant. CKW means were significantly different for: $C L(F=10.56, P=.001)$, CW $(F=6.36, P=.012), P L(F=9.67, P=.002), B D$ $(\mathrm{F}=20.12, \mathrm{P}=.001)$ and weight $(\mathrm{F}=21.56, \mathrm{P}=.001)$ compared to TLK.
ANOVA values for CKW females scored higher means on $\mathrm{CL}(\mathrm{F}=8.35, \mathrm{P}=.004), \mathrm{PL}(\mathrm{F}=8.88, \mathrm{P}=.003)$, $\mathrm{BD}$ $(F=20.46, P=.001)$ and weight $(F=25.35, P=.001)$. Only two ANOVA univariates were significant for males, PW ( $F=8.40, P=.005)$ and $B D(F=9.40, P=.003)$, while all remaining meristics were not significant. The CKW means for PW and BD were higher than TLK; and TLK was higher on CW.

Blood - Fifteen serum values were measured from $M$. $t$. rhizophorarum. Table 2 provides mean values and ranges for M. t. rhizophorarum from both sites together. Small sample sizes prevented testing for any significance between the values of the study sites.

Bacterial Cultures - We successfully analyzed 17 cloacal swabs from which twelve different organisms were isolated (Table 3). The most prevalent shared microbes from both study sites were Clostridium perfringes (59\%), Aeromonas hydrophila (41\%), Providencia rettgeri (35\%) and Proteus mirabilis (35\%). Citrobacter freundii $(24 \%)$, Pseudomonas aeromonas, Serratia marcenes, Salmonella arizona, Clostridium sordelli and Morganella morgani were only isolated on CKW. Escherichia coli and yeast were isolated on TLK.

\section{DISCUSSION}

Results suggest a high degree of fidelity within the mangrove community. Our overall design includes sites across Florida Bay with no significant movement detected after more than eleven years of study. This is additionally supported by the recapture of a number of individuals at CKW marked in the early 1980's by the Earthwatch Institute (Wood pers. comm.). This does not infer that there is not any movement, but our ongoing radio-tracking results coupled with current mark and recapture results show exceptional site fidelity of both the taxon and individuals to mangrove habitat and a particular key. Many individuals marked in a study by Wood (1981) are now microchipped and included within our own as well as his recapture statistics. Likewise in the face of both severe droughts and hurricanes, our study individuals remained highly localized within the mangrove community.

Mark/Recapture - The population at TLK is significantly larger in total number of individuals than CKW. In this respect, our original speculation would be met, despite nearly identical habitat sizes and configurations. The CKW population is half the size as that on TLK and we suggest that this is, in part, a consequence of the constraints given more limited prey availability, but addition- 
Table 3: The microbial results of 17 individual cloacal cultures of Mangrove Diamondback Terrapins (M. t. rhizophorarum) from two study sites. Multiple organisms were shared between the sites. Several organisms isolated were study site specific and represented by TLK or CKW. All samples were taken immediately upon capture.

\begin{tabular}{lrrr}
\hline Microbial Organisms & $\begin{array}{r}\text { No. } \\
\text { Isolated }\end{array}$ & $\begin{array}{r}\text { \% of } \\
\text { Isolations }\end{array}$ & Site \\
\hline \hline Clostridium perfringes & 10 & 59 & Shared \\
Aeromonas hydrophila & 7 & 41 & Shared \\
Providencia rettgeri & 6 & 35 & Shared \\
Proteus mirabilis & 6 & 35 & Shared \\
Citrobacter freundii & 4 & 24 & Shared \\
Escherichia coli & 1 & 6 & TLK \\
Pseudomonas aeromonas & 1 & 6 & CKW \\
Serratia marcescens & 1 & 6 & CKW \\
Salmonella arizona & 1 & 6 & CKW \\
Clostridium sordelli & 1 & 6 & CKW \\
Morganella morgani & 1 & 6 & CKW \\
Yeast & 1 & 6 & TLK \\
\hline
\end{tabular}

al research needs to be conducted to more directly test this statement. We have also considered the possibility that the TLK population may represent a possible intergraded population of the Ornate Diamondback Terrapin, M. t. macrospilota, with the Mangrove Diamondback Terrapin, $M$. t. rhizophorarum based on the more highly variable phenotype encountered there. However, no published study, or our own wider examination of Florida Bay would support size differences as a taxonomic indicator in this terrapin. Ultimately, discovery of detailed genetic variation will be required to delineate the two populations and other subspecies in southern Florida (Miller 2001), especially given the inconclusive recent results from microsatellite DNA analyses (Hauswaldt and Glenn 2005).

Blood - Serum chemistry analysis involves the measurements of naturally occurring enzymes and compounds in the blood, which are the result of metabolic and other physiological processes in reptiles (Mader 2006). The analysis of reptile serum chemistries could have utility for assessing the health of free-ranging reptiles, given sufficient baseline data from natural habitats alongside data from a variety of seasonal and treatment variations. Most values for M. t. rhizophorarum fell within the parameters of other chelonian species (Table 2 ). The $M$. t. rhizophorarum value for alkaline phosphatase (ALKP), $112.08 \mathrm{U} / \mathrm{L}$, is much lower when compared with values for the Trachemys sp., ALKP value of $339 \mathrm{U} / \mathrm{L}$ (Mealey et al., 2002). The Florida Keys Eastern Diamondback Rattlesnake population (Crotalus adamanteus) has higher mean values for TP, uric acid, $\mathrm{CHE}$, LDH and $\mathrm{CL}^{-}$(Mealey et al., 2005). It is notable, even though a small sample size, that there are significant differences between the treatment and control sites for several of these parameters. The application of these serum values within the wildlife management model is still in its infancy. Further studies with augmented sample sizes will be required to determine why the values differ between the sites.

Currently the interpretation of reptile biochemistries is difficult due to the lack of controlled studies and available references. Very often, the avian clinical interpretations are applied to reptiles. For example, depressed $\mathrm{CHE}$ levels are used as an indicator for wildlife exposed to organic phosphate (OP) pesticides. Sanchez-Hernandez (2003) found that CHE activity was a sensitive indicator of exposure in the Tenerife Lizard, Gallotia gallotti, to OP compounds. There is controversy in determining precise $\mathrm{CHE}$ levels acting as an indicator for exposure to OP compounds due to the variations in CHE levels over a short period of time (Mineau et al., 1999).

Our data suggest that certain serum chemistries may be site-specific health indicators, but augmented sample sizes and further analysis must be conducted to better support this contention. The data we collected help establish baseline reference parameters of free-ranging reptiles (Mader 2006). We interpret our results to be representative of wild terrapins and found that all values appear to be within the reported parameters for other reptiles.

Bacterial Cultures - Similarly, the presence of microbial organisms does not signify a compromising infection since a degree of symbiosis occurs (Harwood et al., 1999). Many of the organisms we detected assist in the reptilian digestive process and in the absorption of nutrients. Potential pathogens, (e.g. Salmonella spp.) in humans may be commensal in terrapins and may be acquired through ingesting selected prey and are perhaps eliminated over a period of time. Identifying particular zoonotic microbes such as Salmonella immediately assists researchers by highlighting the necessity of limiting exposure and developing appropriate field hygiene techniques (Becker et al., 2006).

Twelve microbes were isolated from the swabs. Our microbial cultures provide the first measures of these microfauna for free ranging $M$. $t$. rhizophorarum. We found it intriguing that $E$. coli was only found at the treatment site, alongside yeast, both potentially linked to contact with primate feces. The only Salmonella detected was in a sample from the control site. The most abundant flora was shared between both sites and is likely to represent normal bacterial constituents for these terrapins and the surrounding environment. These results are similar to values published for Eastern Diamondback Rattlesnake (Crotalus adamanteus) and the Mangrove Saltmarsh Snake (Nerodia clarkii compressicauda) in the Florida Keys (Mealey et al. 2005). Two strains of Salmonella sp. were isolated from approximately $25 \%$ of the C. adamanteus population. One strain of Salmonella sp. was isolated from two N. C. compressicauda, another mangrove dependent species.

In our examination of these terrapin populations we have documented a degree of fidelity to the mangrove community for this vertebrate that is unique. We are unaware of any taxon, with the possible exception of crocodiles that provides such a continuous occupancy and tight dependence for habitat as shown in the Mangrove Diamondback Terrapin. We have taken advantage of a significant treatment manipulation of a mangrove key in south Florida and evaluated the potential effects on the terrapins living there. Nutrients, particularly phosphorous, likely influence these plant communities, but the terrapins are more likely affected by dietary protein. For the treatment site, the increased protein in both dropped primate diet pellets and influent fecal matter appear to have supported a larger number of individual terrapins, albeit of smaller overall size than the control site. Both blood serum chemistry and microbial flora differed between the two sites, but interpretation of those results is premature. The primates have been removed from the islands as of 2000 due to a court settlement and a mandate by the Florida Fish and Wildlife Conservation Commission. Our current work will seek to evaluate the trend for the treatment population as the system returns to the natural regime, although we predict it will be several 
years before a clear response is detectable. While often overlooked in evaluations of the mangrove ecosystem, reptile components are both dependent and tightly integrated within these communities, potentially providing valuable vertebrate models for the study of these ecosystems.

\section{ACKNOWLEDGEMENTS}

We are indebted Charles River Lab and the Key West National Wildlife Refuge for granting access to the study sites. AVID, Inc. for the donation of scanners and PIT tag equipment for marking the terrapins. Our sincerest appreciation to B. \& F. Ford, L. A. Latino, C. Pages, Lt. P. Reynolds and T. Wilmers for their assistance in facilitating our work with terrapins. The Batchelor Foundation, Inc. and the USGS for providing funding for this project. J. Lani and T. Cross from Statistical Solutions for their assistance with data analysis and interpretation. The Wetlands Institute, Inc. and Dr. Roger Wood for their knowledge and cooperation.

\section{LITERATURE CITED}

Baldwin, J. D., L. A. Latino, B. K. Mealey, G. M. Parks, and M. R. J. Forstner. 2005. The Diamondback Terrapin in Florida Bay and the Florida Keys: Insights into Turtle Conservation and Ecology. Pages 180186 in W.E. Meshaka and K. J. Babbitt, Eds. Amphibians and Reptiles: Status and Conservation in Florida. Krieger Publishing Company, Florida.

Becker, D., M. Selbach, C. Rollenhagen, M. Ballmaier, T. F. Meyer, M. Mann, and D. Bumann. 2006. Robust Salmonella metabolism limits possibilities for new antimicrobials. Nature, Vol. 440, pp: 303-307.

Camper, J. D. and J. R. Dixon. 1988. Evaluation of a microchip marking system for amphibians and reptiles. Texas Parks and Wildlife Dept. Res. Publ. 7100-159: 1-22.

Draud, M., M. Bossert, and S. Zimnavoda. 2004. Predation on hatchling and juvenile Diamondback Terrapins (Malaclemys terrapin) by the Norway rat (Rattus norvegicus). Jour. of Herp. Vol. 38, No. 3, pp: 467-470.

Forstner, M. R. J., Parks, G. M., Miller L., Herbert B., Halbrook, K. and Mealey, B. K. 2000. Genetic variability and geographic structure of Malaclemys terrapin, populations in Texas and south Florida. A report to the Species at Risk Program of the United States
Geological Survey.

Harwood, J. Valerie, Butler, J., Parrish, D. and Wagner, V. 1999. Isolation of fecal coliform bacteria from the Diamondback Terrapin (Malaclemys terrapin centrata). Appl. and Environ. Microbiol. Vol. 65 2: 865867.

Hauswaldt, J. S. and T. C. Glen. 2005. Population genetics of the diamondback terrapin (Malaclemys terrapin). Mole. Ecol. 14:723-732.

Mader, D. R., 2006. Reptile Medicine and Surgery. $2^{\text {nd }}$ Edition, Saunders Elsevier Inc., St. Louis. MO 1242pp.

Mealey, B. K. G. M. Parks, J. Schooley, J. Rothchild, L. Roth, D. Snodgrass, and J. D. Baldwin. 2002. Discovery of Freshwater Turtles in Bimini, Bahamas. Bah. J. of Sci. 9(2): 45-53.

Mealey, B. K. G. M. Parks, M. A. Perez, J. D, Baldwin, and M. R. J. Forstner. 2005. Insular Ecology of Florida Keys Reptiles. Pages 171-179 in W.E. Meshaka and K. J. Babbitt, Eds. Amphibians and Reptiles: Status and Conservation in Florida. Krieger Publishing Company, Malabar, Florida.

Miller, L. A. 2001. Population status and potential storm dispersal events of Malaclemys terrapin in Florida Bay, Florida. Master Thesis. Florida Atlantic University, Davie, Florida.

Mineau, P., M.R. Fletcher, L.C. Glazer, N.J. Thomas, C. Brassard, L.K. Wilson, J.E. Elliott, L.A. Lyon, C.J. Henny, T. Bollinger, and S.L. Porter. 1999. Poisoning of raptors with organophosphorus pesticides with emphasis on Canada, U.S. and U.K. J. Raptor Res. 33(1): 1-37.

Roosenburg, W. M. and J. P. Green. 2000. The impact of a bycatch reduction device on diamondback terrapin and blue crab capture in crab pots. Ecol. Appl. 10:882-889.

Sanchez-Hernandez, J, C. 2003. Evaluation reptile exposure to cholinesterase-inhibiting agrochemicals by serum butylrylcholinesterase activity. Environ. Toxicol. Chem. Vol. 22 (2): 296-301.

Seigel, R. A. and J. W. Gibbons. 1995. Workshop on the ecology, status, and management of the Diamondback Terrapin (Malaclemys terrapin), Savannah River Ecology Laboratory, 2 August 1994: final results and recommendations. Chel. Cons. Biol. 1:240-243. Wood, R. C. 1981. The mysterious mangrove terrapin. Fla. Nat. 54:6-7. 